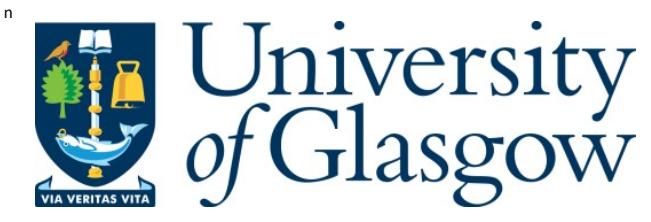

A skins, K . (2009) Crossing divides: ethnicity and rurality. J ournal of Rural Studies, 25 (4). pp. 365-375. ISSN 0743-0167

Copyright (c 2009 Elsevier

A copy can be downloaded for personal non-commercial research or study, without prior permission or charge

Content must not be changed in any way or reproduced in any format or medium without the formal permission of the copyright holder(s)

http://eprints.gla.ac.uk/98362/

Deposited on: 16 October 2014

Enlighten - Research publications by members of the University of Glasgow http://eprints.gla.ac.uk 


\section{Crossing divides: ethnicity and rurality}

\section{Abstract}

This paper draws on research with people from African, Caribbean and Asian backgrounds regarding perceptions and use of the English countryside. I explore the complex ways in which the category 'rural' was constructed as both essentialised and relational: how the countryside was understood most definitely as 'not-city' but also, at the same time, the English countryside was conceived as part of a range of networks: one site in a web of 'nature places' across the country, as well as one rural in an international chain of rurals - specifically via embodied and emotional connections with 'nature'. I argue that alongside sensed/sensual embodiment (the non-representational intuitive work of the body), we need also to consider reflective embodiment as a desire to space/place in order to address the structural socio-spatial exclusions endemic in (rural) England and how they are challenged. I suggest that a more progressive conceptualisation of rurality - a 'transrural' open to issues of mobility and desire - can help us disrupt dominant notions of rural England as only an exclusionary white space, and reposition it as a site within multicultural, multiethnic, transnational and mobile social Imaginaries.

Key words: ethnicity, nature, embodiment, materiality, transrural 


\section{Crossing divides: ethnicity and rurality}

\section{Kye Askins}

\section{On positioning}

I am feeling somewhat ambivalent about this special issue. On the one hand, I'm excitedly anticipating sustained engagement with issues surrounding ethnic identity construction, rurality, and social and spatial in/exclusion - on the other, l'm regretting that such an issue wasn't compiled a few years ago when I was researching my $\mathrm{PhD}$, concerning these issues. The case that ethnicity has been under-examined within rural studies will, no doubt, have been made in the 'Introduction' to this volume. While I repeat it here, I'd like to do so by positioning myself in/through some of the relevant academic literature, mindful of feminist debates regarding the part that we, as individuals, play in our academic endeavours and the need to excavate and hold central those lived experiences and 'situated knowledges': the need to reflectively examine the ways in which we are positioned and position ourselves in a variety of contexts, recognising the inseparability of consciousness and embodied experiences, and how these subjectivities are caught up with a 'politics of position' (eg. Bondi, 2002; Kobayashi, 1994; Rose, 1997).

My PhD journey took place between 2000 and 2004, and focussed on the perceptions and use of the English national parks ${ }^{1}$ among people from Asian, African and Caribbean backgrounds. More broadly, I explored issues regarding ethnicity, rurality and national belonging in contemporary England, and was tasked with writing a policy report alongside the thesis ${ }^{2}$. As I read the academic work around my research, I increasingly became aware of a dichotomy. There was a rich body of literature around ethnic identity, diversity, hybridity, multiculturalism, cosmopolitanism, etc., including critical perspectives problematising these concepts and how they play out in society, but always and only embedded in the urban sphere (eg. Alexander, 2000; Amin, 2002; Back and Solomos, 2003; Brah,et al. 1999; Hesse, 2000; Mirza, 1997; Parekh, 2000a; 2000b). At the same time, especially within geography, there was interest in the ways in which rurality/rural space is implicated within national identity construction, notions of belonging and spatial practices ${ }^{3}$. In the English context, the national imagery of rural space appeared to exclude ethnic minorities, among other groups, from accessing the countryside, both physically and emotionally (Cloke \& Little, 1997; Milbourne, 1997). The connection between the rural as the 'genuine' England and not multicultural was highlighted in the 
literature as replayed and reiterated throughout representations of Englishness (Matless, 1998; Scruton, 2001).

Certainly, academic work relating such racialisation of the countryside to the absence of ethnic minorities in rural areas had been central in opening up debates about racism and social exclusion in the countryside. For example, Neal (2002) outlines a policy impotence and even arrogance in rural areas regarding the (non)-relevancy of ethnicity as a rural concern. Unpacking the 'rural idyll', then, was crucial in disrupting the stereotyped homogeneous, white countryside being folded into constructions of Englishness, heritage and cultural 'norms' (Agyeman, 1995; Agyeman and Spooner, 1997; Henderson and Kaur, 1999; Kinsman, 1995; Malik, 1992). However, there had been a lack of empirical work at that time to examine these issues further: ethnic minorities were perhaps too easily theorised and written as excluded 'rural others'. Indeed, Little (1999:438) voiced concern regarding the use of the term 'rural others' in general, "the lack of theoretical discussion around 'the other' and 'the same'”, the paucity of recognition of the power relations complicit in such a categorisation, and the "static treatment of both individual and group identity".

This urban-as-multicultural and rural-as-monocultural dialectic was paralleled in conference and seminar settings: if I wanted to engage with debates on 'race' and ethnicity, I went to sessions on 'cities' or 'urbanism' or 'everyday urban life', otherwise I explored conceptual work regarding 'the rural' in rural sessions/events that were largely devoid of any mention of ethnicity. My fieldwork, however, was problematising such categorisation. To talk with people from Asian, African and Caribbean backgrounds, much of my empirical research was certainly conducted in urban areas, but these groups were also visitors to national parks, independent of those visits organised as part of the research itself (see methodological outline below); I was also talking with national park staff and 'countryside/heritage experts' (not quite all of whom were white) often in urban settings. It seemed that I was continually crossing spatial and social divides. This was mirrored in my personal life. I'm a white woman, who ticks 'British' on monitoring forms but would describe myself as Anglo-Irish - and who I am/how I am perceived 'had a relation to what 'truths' and accounts' I was told by my respondents (Neal and Walters, 2006). But also my extended family includes Native American Indian and African ethnicities, and over the period I was researching the $\mathrm{PhD}$ I spent time with family members from different backgrounds in different UK settings, rural and urban. Notions of any easy 
separation, then, between a white rural and diverse ethnic urban in contemporary England were challenged in a range of ways and places.

And so I want to offer some reflections here on the understandings and use of rural space among people from diverse ethnic backgrounds, paying close attention to what emerged from the research as the need to think the category 'rural' in more open/inclusive ways. Towards the end of the paper, I suggest the concept of transrurality as a more progressive conceptualisation of rurality, one that both encapsulates the specificities of place and is open to mobility and desire - in order to displace rural England as only an exclusionary white space and reposition it as a site within multicultural, multiethnic, transnational and mobile social Imaginaries. Such thinking stems from the complex ways in which the category 'rural' was constructed by research participants as essentialised and relational: how it was understood most definitely as 'not-city' but also, at the same time, how the English countryside was conceived as part of a range of networks - one 'nature site' in a web of national 'nature places', as well as one rural in an international chain of rurals - specifically via values attached to notions of nature.

Indeed, the paper begins by considering the role of 'nature' in visible community perceptions and use of rural spaces. For many participants, positive attachments to 'nature' challenged the dominant construction among countryside organisation staff, which tied visible community absence from rural areas to a non-appreciation of nature fixed to ethnic difference. However, diffidence and other negative responses were suggestive of more diverse opinions among visible communities, disrupting any essentialisiam regarding ethnic readings of nature. Such complexities, I propose, can be understood through paying attention to materiality, the embodied experiences it affords in place and space, and its attendant role in social Imaginaries and spatial practices. I suggest that alongside corporeal, sensual embodiment (the non-representational intuitive work of the body), we need also to consider reflective embodiment as a desire to space/place in order to address the structural sociospatial exclusions endemic in (rural) England and how they are challenged. As such, the paper builds an argument for greater focus on the 'transrural' as a perspective which helps us move beyond an urban-as-multicultural and rural-as-monocultural paradigm. 
Of course, study and debate on these issues continually develops. Exciting work on 'ethnicity' and 'rurality' is emerging that problematises the urban-as-multicultural and rural-as-monocultural dichotomy (see Bressey, 2009; Panelli et al., 2008; Tolia-Kelly, 2004; 2006a; 2007), and challenges singular notions of and experiences in 'the rural' (Neal and Agyeman, 2006). There are also new approaches to 'landscape' and space/place in terms of embodiment and affect (Macpherson, 2009a; Massey, 2006; Probyn, 2005; Rose, 2006; Tolia-Kelly, 2006b; Wylie, 2005). I draw on these literatures in revisiting my PhD work. I too have moved on. I'm now a lecturer in geography in an urban university, doing ethnographic research with refugees and asylum seekers in an inner city area of Newcastle-upon-Tyne (northern England), which has included going on day trips to nearby countryside. These more recent experiences are also, inevitably, be folded through reflections on previous research.

\section{On methodology and 're-presentation'}

The paper draws on a range of empirical methodologies undertaken for my PhD. Case study sites were the cities of Middlesbrough and Sheffield and the respectively adjacent North York Moors (NYM) and Peak District (PD) national parks (see Figure 1). Quantitative data was collected via face-to-face questionnaires with people from Asian, African and Caribbean backgrounds, referred to as 'the urban survey' (310 responses in Middlesbrough, 296 in Sheffield ${ }^{4}$ ), and with visitors in the national parks, referred to as 'the visitor survey' (295 responses in the NYM, 300 in the PD, $8 \%$ identified as nonwhite ${ }^{5}$ ). A postal questionnaire survey was also carried out with residents in the national parks, 'the resident survey' (988 responses, 65\% response rate, over 99\% identified as white).

Qualitative work comprised six focus group interviews and twenty individual in-depth interviews with 'visible communities' (see below) in Middlesbrough and Sheffield ${ }^{6}$. In addition, six focus group interviews with national park staff were completed, three each in the NYM and PD, at senior management and operational management levels, as well as with staff who engage with the public (all of whom identified as white). Two focus group interviews were conducted with national park Committee Members, who are responsible for policy-making (one person identified as Asian British, the rest as white). Finally, ten interviews were undertaken with professional 'stakeholders' working 
across a range of countryside and/or 'national heritage' organisations (one person identified as Black British, one as Chinese British, the rest as white). Participant observation occurred during day visits to the national parks, organised for each visible community focus group participating in the research, and also during six visible community residential trips (three to five days long) organised by the Mosaic Project, a three-year initiative co-managed by the Council for National Parks (CNP) and Black Environment Network (BEN) ${ }^{7}$.

[insert Figure 1 here]

Terminology around ethnicity is highly problematic. After a great deal of reflection and debate with many of the research participants, I chose to use the term 'visible communities' (after Alibhai-Brown, 2001) in the academic and policy writing up. I first opted for this term to avoid both the homogenising tendencies of the term 'black' (as critiqued by Modood, 1992) and the power-laden term 'minority'. 'Visible communities' is not intended to reify visible difference from a white 'norm', but I use it as a political signifier to highlight that there are power inequalities endemic in English society, which are commonly grounded in perceptions of inferiority and threat attached to visible difference from a white 'norm' - especially in the English countryside. I have stayed with the phrase here for these same reasons, and also in respect for the research participants, the majority of whom agreed on its use in representing the study.

Also, there is a need to outline some slippage between the concepts of 'national park', 'the countryside' and 'the rural'. While the research set out to examine perceptions of national parks, visible communities discussed 'the countryside' and talked about 'rural areas', using the terms interchangeably and defining them generally as "the same thing". There was little awareness of the existence of national parks as organisations or defined areas of land among visible community respondents ${ }^{8}$, and the term landscape was rarely employed. Thus, in this paper I use the terms 'countryside' and 'rural' as far as possible in line with how respondents used them, while recognising the analytical issues associated with doing so. 


\section{3. (Mis)perceptions: on nature and ethnicity}

Whatmore (1999:7) argues that 'ways of seeing' the natural world share three common principles: the representation of nature is not a neutral process, but instrumental in constructing our sense of and values regarding the natural world; representations are, therefore, established repertoires of cultural reference points which "repeat and ricochet off one another down the ages", and shift from being understood as depictions of what nature is to blueprints of what nature should be like; and there are many incompatible "ways of seeing the same natural phenomenon, event or environment". Indeed, the idea that nature is socially constructed is an established understanding within social science, linking different perceptions of nature to different groups. Harrison \& Burgess (1994:298) write that the construction of nature takes place within social groups, resulting in a nature 'myth'. Such myths function:

"as a cultural filter so that adherents are predisposed to learn different things about the environment and to construct different knowledges of it. In this way, beliefs about nature and society's relationship with it, are linked with particular rationalities that support the modes of action appropriate for sustaining these myths."

The idea of a cultural filter suggests that within 'same' cultural groups perceptions of nature are accordant. What became clear in the research was that 'cultural nature myths' also explicitly involve constructing 'other' groups as having different 'nature myths' and a different appreciation of nature, because they are of different ethnic background, in line with Geertz' (1963) notion of 'primordial ethnicity'. For example, there was a strong tendency among national park staff and across the resident and visitor surveys to portray people from visible communities as having a different culture, and therefore different perspectives of nature, precisely through structured understandings of essential differences between cultures tied to reductive versions of ethnicity. Difference to what or whom was rarely specified, but focus group discussions implicitly assumed the difference to be from the majority 'white' culture:

[discussing what may prevent 'ethnic minorities' coming to the national park] 
M1 their own culture

KA in what way?

M1 well they have a cultural thing that they have big family gatherings where they live rather than coming out into the national parks or or coming out into the countryside

F1 $\quad I I \ldots$

M2 well I think that's a generational thing so/

M3 /yes

M1 the older generation have got this cultural thing

F1 I mean I don't know a lot about these cultural groups I should think a lot of them the women don't socialise I mean it's the men socialise at the mosque or whatever ... but nature isn't a big thing for them is it

(Focus group with face-to-face staff in the PD)

Similarly, in another discussion:

F1 maybe they'd rather do something else with their spare time

M4 I was gonna say aren't we being rather arrogant in assuming they'd want that ... have would have an interest in the countryside/

M2 Ithey haven't got the information to start with though the the information's purveyed erm I sense erm particularly through the wrong places and in the wrong language and at the wrong time so they don't have the information to make a sound decision ... so I don't think we can ... assess whether they want to come or don't want to come/

M4 Ino l'm not saying that/

F1 Ino no no 
M4 II'm not saying that I I'm saying that um an' and you're right we should be the information ... but we should also be well aware that they may just simply not have an interest/

F1 /that even if they knew we were here they might not want to come/

M4 Inot want to come

M3 culturally it's not something they coming to the countryside isn't ... what those groups want ... might not be what they do

(Focus group with senior management in the NYM)

While there was some awareness of diversity within visible communities, it was minor in a dominant discourse that essentialised and conflated 'culture' and 'ethnicity': many comments surrounded the notion that nature and wildlife lack positive significance for visible communities - rather that rural areas have negative connotations as places of work and poverty in countries of origin. This 'Others' nature' myth reiterates/replaces visible communities as belonging/being in cities, not countryside, through easy slippages between ethnicity, 'race' and place, as well as conflating nature with countryside. Such reductive thinking, though, was refuted by visible communities themselves in the urban questionnaire survey:

[Insert Table 1 here]

The $72 \%$ who agreed/strongly agreed that nature was important to their self identity came from a cross-section of gender and class positions, and this sentiment was supported by many visible community interviewees. It was also clear on most focus group day trips to the NYM/PD, and during the Mosaic residential visits, that nature is central to some visible communities' ethnic identity, inherent within cultural practices and also religious beliefs. One group explicitly structured their Mosaic visit around linking wildlife and nature to their personal and communal spiritual identity and growth. The idea that visible communities in England may attach importance to being in natural environments suggests that there are commonalities across visible community and non-visible 
community cultures $^{9}$, further borne out through the on-going work of the Mosaic Partnership ${ }^{10}$ and the long term vocation of the Black Environment Network ${ }^{11}$. Indeed, a humanistic discourse emerged through much of the conversation during participant observation, in which many visible communities described feeling happiness and joy to be in countryside, connected to a 'love' of nature - with the word 'love' used surprisingly often.

[insert Figure 2 here]

However, there is a danger of replacing one determinist account with another, and it is not my intention to foreground here those versions of indigenous or 'developing world' ethnic groups as conceiving nature to be integral to 'their' society which litter many anthropological accounts (O'Riordan, 1989). Lowenthal (1997:234) cites such 'regressive environmental and racial determinisms' as enabling a 'mystique of the indigene as ecologist', in which non-white communities are produced as environment-protectors, equally fixing the 'other' and 'their' culture through how 'they' understand and relate to nature (see also Braun, 2002; Nakashima, 2003). As Brah et al. (1999:2) stress:

"the actuality of these ethnic and sexual categories and divisions is more contradictory, fragmented, shifting and ambivalent than that suggested by the dominant public definitions of these categories."

We need, rather, to examine how power relations and social inequalities are caught up in spatial struggles over nature (Katz, 1998).

Certainly, indifference to, dislike of and/or feelings of exclusion from the rural were also evident in the research: "Going to the countryside, nature and that - that's just not something we do" was a phrase common among some visible community participants, as part of a discourse iterating 'black people' and 'Asians' as having different culture from dominant white majority. Rather than simply mirroring the dominant national park staff narrative, though, there are complex issues surrounding 'strategic essentialism' and identity politics involved in such essentialist/essentialising constructions of visible community-ness among visible communities that I have tried to address elsewhere (Askins, 2006; see 
also Gilroy, 2001; Hall, 2003; Hesse, 2000). Importantly, socio-economic position among visible communities is embedded in majority/minority social inequalities in England (Sivanandan, 2001), and throughout the research, most 'anti-nature' discourses encountered in fieldwork were partly articulated through resistance to exclusion and racism in English society more broadly.

For example, it was instructive that 'community leaders' in particular utilised a 'black people don't go to the countryside' discourse, while often distancing themselves from this visible community 'norm'. One founder and director of a visible community organisation in Middlesbrough described walking in the NYM as "second nature", and valued the rural as part of his everyday life and culture as a "British Hindu', specifically in a middle class position. But he was adamant that visible communities in Middlesbrough do not go to the countryside, because they do not have the financial resources or spare time, and because they would not be welcomed. He spoke of the "racism that holds my community back", ambivalently claiming the rural for himself personally, but not for visible communities more widely. Among people 'spoken for' in such accounts, however, the picture was complicated by a diverse range of productions of and responses to nature. For instance, there was a significant difference across age: $61 \%$ of urban survey respondents aged $15-24$ years strongly disagreed/disagreed that nature was important to them, the only age group where the negative response was in the majority ${ }^{12}$.

Nature and the countryside may well be understood through 'cultural filters', then, but these can be as much embedded in age, gender and socio-economic class positions as ethnicity. I want to move on, then, to consider how these diverse sensibilities had distinct implications for spatial practices, in particular through accounts of (perceived) physical properties of the countryside and associated experiences of being in nature: specifically, how a strong understanding of rural as affording 'natural' experiences led to both positive and negative attachments that cut across any easy ethnic categorisations.

\section{Unpacking ethnicity: on materiality and embodiment}

Recently, there has been somewhat of a 'material turn' in geography and the social sciences (Anderson and Tolia-Kelly, 2004; Jackson, 2000), exploring how matter/materiality are caught up in 
socio-spatial processes and practices. Mindful of conceptual debates surrounding conflicting 'materialisms', and of Kearns' (2003) warning regarding the 'wayward expressiveness of matter' that facilitates active capacities outside its relation with the subject, the research suggests that paying attention to the ways in which sensuous experiences and spatialities are generative of the bodysubject are critical when thinking about ethnicity and rurality.

Indeed, the ways in which we form and reform ourselves in and through materiality and sensing place have increasingly been explored through work on embodied experiences in 'landscape' (eg. Massey, 2006; Wylie, 2005). Hetherington $(1997 ; 2003)$ writes that both subjects and objects (referring to people and places) are folded into each other, and that agency is less the exclusive privilege of the subject but rather the effect of the entanglements between subject and object. If we consider the rural as, in part, material object, these mutually constitutive relationships between place and identity mean that the physical countryside is intertwined with people's understandings of rural space and themselves in rural space.

Such thinking resonates with key findings that emerged through the research. Most crucially, the construction of a rural-urban divide was clearly evident among ALL research participants, in which the underlying constant was a physical, essential(ised) difference between city and countryside precisely through sensory experiences in place, or understandings of what embodied physical experiences in the countryside would involve. The rural was repeated as a given, definable landscape understood as the antithesis of the city: the physical environment of the countryside as the opposite of a city environment, with positive attributes opposed to city negatives. Common descriptions of the countryside included 'less pollution and less cars than in the city'; 'not built up like the city'; 'much quieter than the towns'; 'where people go on trips to get away from the city'; and 'not as many people as in the city'. This rural 'idyll' was produced via the urban as non-idyllic through notions of natural and not-natural:

F1 yeah fresh air you know ... clean air for health and the kids ... yeah clean fresh air [another women emphasises this point in the background] ... all the pollution in the town here and in the countryside it's fresh air 
F3 $\quad \mathrm{mmm}$

[all agree verbally, many also nod their heads]

(Sheffield visible community focus group: 3 women and 5 men, 45-64, identified as Black British, Afro Caribbean or both)

In addition, there was a therapeutic value associated with being away from the city, again explicitly linked to the physical differences between urban and rural landscapes. For many visible community participants, city living was equated with stress, and not being in the city with relieving stress:

B1 sometimes possibly just a place to I would probably go for a place to go and and get away from the ... the everyday city environments ... and have nice time to yourself it's peaceful (Individual interview in Middlesbrough: man, 25-34, Pakistani)

B4 I like to walk the Castle Eden way you know ... the walkway ... after work ... it's so quiet and you're in the countryside and away from from the stress of the city (Individual interview in Middlesbrough: woman, 45-54, British Asian)

Indeed, the 'peace and quiet' of the countryside was mentioned in every interview, and connected to a desire to go to rural areas among many visible community participants (see Parr, 2007 regarding perceived health benefits of nature/being in natural surroundings). While nature cannot be conflated with the rural, the rural remains the most commonly defined spatialisation of nature (Cloke et al., 1996) - but it is articulation around what 'being in' the countryside is/will be like that suggests a need to move beyond understanding nature and place as only socially constructed, and consider how landscape is sensed. In particular, paying attention to embodied experiences can help us challenge reductionist thinking around ethnicity and rurality. 
As mentioned earlier, for example, there were clear generational differences among visible community respondents to the urban survey, but a majority of under $25 \mathrm{~s}$ across both the urban and visitor surveys strongly disagreed/disagreed that "national parks can be enjoyed by people of all ages", believing that the countryside is for 'older people'. More specifically, a lack of interest in visiting rural areas among 15-24 year olds in the urban survey ${ }^{13}$ was predominantly connected to the ways in which nature was conceived, while in the visitor and resident surveys this age group was least represented. These results echo national park and broader countryside/heritage organisations' experience that the late teens and early twenties are 'the missing years' in terms of engagement with rural areas, highlighted in all stakeholder interviews and national park focus groups ${ }^{14}$ (see NYM, 2003).

Although younger visible community participants involved in Mosaic visits and focus group day trips were more positive about being in the countryside, they specifically participated in activities such as kayaking, abseiling, archery, climbing and ropes courses - physical and 'exciting' activities. Young people's engagements with the rural were dynamic, making and being made by a range of materialities afforded by more than the natural environment: by human-made boats, bows, ropes and other equipment, suggesting the body-as-hybrid and identity production through the ways in which the body is 'put to use' (see Whatmore, 2002). This is not to say walking wasn't enjoyed by younger participants, but most doubted they would return to the countryside 'just' for a walk or 'to look around the villages'. While going for a walk may involve a range of physical experiences/stimulations/ affordances (see Ingold and Lee, 2008), younger participants constructed themselves as needing 'more' than what they thought and felt a walk offered: younger identities were performed through dynamic/extreme corporeal sensibilities such as thrill, adrenaline, excitement and exhaustion.

[insert Figure 3 here]

Participants from older age groups articulated their enthusiasm to return irrespective of any planned activity, many recounting feelings of contentment 'to sit and look at the view' or 'listen to the birds/enjoy the quiet'. The countryside was more reflectively embodied, and within a somewhat 
different range of emotional registers - older participants often discussed memories prompted through sensuous experiences. Of course, any generalisation of social categories risks reduction: there are issues here beyond the scope of this paper regarding 'normalised' bodies and physical activity (MacPherson, 2009b), and ageist accounts of body ability. But this research strongly suggests that age plays a key role in experiencing the countryside across a range of ethnic groups, more broadly supporting Merriman et al.'s (2008:192) contention that we should examine

"how landscape/landscaping is practiced, emergent through mobile and material practices, and how mobilities animate landscapes and places, and are inseparable from particular materialities."

Furthermore, gender differences were apparent across the research. Among women in particular, issues of safety were commonly linked to how physically isolated rural areas are, and anxieties around being alone and/or stranded in the countryside: 'what if the bus doesn't come/our car breaks down?'; 'if someone falls over, there's no one around to help'. There were also practical concerns connected to the body, especially linked to caring roles and looking after children's physical needs: 'it's difficult to get food and drink in villages'; 'are there public toilets?'. While this broad gender difference is cross-cut by other factors (most notably class, see Askins, 2006), generally men felt less fear (or articulated less fear) about being in rural areas: such a gendered engagement with rurality has been well documented elsewhere (eg. Little, 2002; Little and Austin, 1996).

The point here is that a material reading of embodied rural-as-nature disrupts any easy production of visible communities as 'rural others', and sensory experiences of nature and/in place were generative of complex productions of the English countryside among visible communities. While the (real and perceived) physical geographies of rurality enabled/reconstructed a rural-urban binary, at the same time it was precisely such embodied, sensory engagements with 'nature places' which also allowed for relational understandings of space. Two distinct networks emerged from the research: an international web of rural areas understood in relation to one another; and a continuum of sites in which nature was present, across rural and urban areas in England. It is to these transrural Imaginaries, constructions and experiences that I now turn. 


\section{Across spatial divides: on 'nature places'}

Franklin (2002:190) outlines a need to "understand nature also as a spatially disembeddable, fragmentable notion (in time and space)", and the research points to the centrality of physical experiences in such a conceptualisation. The English countryside was connected to countrysides across the world through a 'thick' understanding of materiality linked to notions of the rural-urban binary: rurals were connected by their non-urbanness. During participant observation, direct comparisons were made between the hills in the PD and the foothills of the Himalayas/the Blue Mountains in Jamaica/various hilly areas across Africa; coastal areas of the NYM were compared with coastal parts of the Caribbean, Senegal, India and Sri Lanka; and villages in both national parks were associated with villages in (grand/parental) countries of origin, by first, second and third generation participants. While the physical geographies of the places concerned often differed widely, important was that different rurals were understood to offer the same 'natural' attributes outlined earlier in the paper: fresh air, less development, fewer people, beautiful scenery, and peace and quiet dominated such comparative discourse. Interestingly, even accepted/recognised difference didn't detract from relating between different rurals:

S3 I mean OK so you don't haven't got lions and hippopotamus and giraffes like in parts of Africa ... umm but it's the same thing ...animals in the wild and open views and ... all of that it's all countryside

(Individual interview in Sheffield: man, 35-44, Ghanaian)

B7 it's the same ... countryside here and in India ... OK it looks a bit different our hills are ... they have proper mountains here we have hills ... but it feels the same

(Individual interview in Middlesbrough: woman 25-34, British Asian)

The second quote in particular suggests the importance of registers other than visual. While the visual sense remained central in rural experiences across the study - scenery and views were commonly 
quoted as key reasons for going to the countryside, and the 'eye/l' privileged in perceptions of the natural world (see Anderson, 1995) - other senses were also involved, especially the aural, olfactory, and tactile. For example, on a day trip to a coastal village in the NYM, one woman (30 years old, second generation Asian British) stopped while wandering around narrow residential lanes on a steep hillside above the beach. It was a warm day and there was a pervading smell of sea air/salt mixed with faintly rotting washed-up seaweed. She explained that she'd worked out what the smell reminded her of: her grandmother's village in rural Pakistan, which she had visited the previous year. She spoke about the wonderful time she'd had 'there', and how much she loved the countryside 'here' because it was 'just like there' ... and compared the villages as being 'really similar'. Later, when I asked the woman to describe her grandmother's village, it became clear that physically these were very different places - the Pakistani village was inland, flat and very dry. The smell that she'd recognised was that of "rotting stuff - not very bad just in the background", due to there being a lack of drainage and waste disposal systems in her grandmother's village. In addition, she identified the warm sun on her skin as another trigger to memories of Pakistan.

Experiences in the rural, then, involve a range of sensory interactions with nature. De-centring sight helps us to move away from the ontological given of visual identification, and better understand the embodied spatial relations that draw upon connections made through smell, hearing, taste and touch (Edensor, 2007). Importantly, Pink (2007) describes the complex interconnectedness of senses, in which embodiment involves the transferral of meanings across different senses as well as across space and time. Conceptualising such links between senses opens up thinking about mobility, memory and emotion. It was this kind of complex, transferrable embodiment which also disturbed the rural-urban binary, through productions of 'nature places' across the rural-urban divide - paradoxically often alongside constructions of such a boundary. Country parks, urban parks, green open spaces and gardens were all understood as parts of a network of 'nature places' across England:

S4 I find it therapeutic to walk in greenery I just love greenery ... trees and you know l'm a very outsidey kind of person ... um I think it [the countryside]'s a place where you feel at peace at one with yourself [laughs] I'm getting deep now [laughs] um ... like my garden [...] I sit out in my garden and 
hear the natural noises the nature you know ... and see the plants smell the flowers and ... feel the wind you know

(Individual interview in Sheffield: woman, 35-44, Black British)

For this woman, nature was an important part of her life, and she went on to talk about walking frequently in the countryside on the edge of Sheffield, as well as in her local park, in particular enjoying seasonal change. For another group on a residential visit to the PD, it was the experience of 'picnicking' that afforded connections across city and country: sitting on the (slightly damp) grass and eating sandwiches with the wind blowing on their faces, prompted shared remembrances of days spent in an urban park in Sheffield.

[insert Figure 4 here]

Such narratives beg consideration of 'non-representational theory' and the ways in which precognitive embodied experiences may be integral to conceptions of self identity and spatial practices through landscape as performed, enactive and emergent (see Lorimer (2008) for an overview of the important contributions NRT is making within geographical thinking). While I believe the research highlights the importance of paying closer attention to everyday sensual embodiment-as-habit (the intuitive work of the body) with regards to nature, my point in this paper is that only considering unreflective embodiment can limit 'belonging' to everyday physical environments. Macnaughton and Urry (2000) argue for a critical engagement that recognises embodied practices as (also) reflective, and open to how physical experiences are used to express identity, claim status and convey cultural and personal values. Furthermore, Tolia-Kelly (2007:337) warns us against unproblematically theorising 'intuitive' embodied landscape performances that do not take into account:

"an increased acknowledgement of the place of difference and power in shaping the matrices within which "we" can engage with landscape". 
Certainly, racist exclusion was experienced by some participants who had been to the English countryside, and was expected by others who hadn't:

B1 I have I've visited er the Moors [NYM] with a friend of mine and ... we went round she showed me a few places with a number of other people from work ... and then we went in for a drink in this pub ... and it was ... OOF ... you know as if NO WAY you know what are YOU guys doing here and ... I've never actually wanted to go back ...

(Individual interview in Middlesbrough: man, 25-34, Pakistani)

And among a group who had never been in the English countryside at that point:

F2 it's really English people that don't like um ... our type of culture/

F3 /clothes and stuff

[all talk together, about rejection of their 'way of life' in England by the English/white majority]

F2 they want us out of England really

[some laughter, some disagreement]

F2 no they DO though

F7 I don't think you [to interviewer] want us to come out to the countryside

F? no

F5 we wouldn't be wanted there [countryside]

[general agreement]

(Middlesbrough visible community focus group: 8 women, 16-20, all identified as British Asian)

It is critical to face up to racism and highlight its myriad implications in how rurality is experienced and perceived, with regard to the English countryside. For example, Robinson (2008) outlines that 'white 
flight' occurs from multiethnic cities to rural villages precisely because these areas are constructed as white in the dominant social Imaginary, which in turn impacts social relations in those areas (see Ray and Reed (2005) on racism in semi-rural Kent). There is a danger that if we take the non-reflective continuity of everyday experiences and continually repeated bodily practices as constituting cultural practices, then landscape as 'practiced' limits visible communities to certain cultural practices in certain spaces, namely the urban where 'they' predominantly live in England - a presumption evidenced in the earlier quotes from national park staff focus groups (see also Askins, 2008).

Instead, the research suggests both a need to hold NRT's corporeal, emergent sensibilities alongside reflective reworkings of place-making, and recognise a tension between the social construction of identity and space, and embodied experiences of place. Massumi's (2002) concept of a nature-culture continuum is helpful here, in thinking through how the 'natural' and the 'cultural' are mutually constitutive of each other, to the degree that we can't maintain distinctions between them. It's not that 'nature' as matter is only a physical experience, defined by our sensuous encounters with it; nor is 'nature' only represented, understandable solely through socialised narratives and texts. Rather, these move into and through each other in continual re-makings of subjects and objects. (There are also important links here with an increasing body of work on 'urban nature' which problematises the nature-culture binary, eg. Hinchcliffe et al., 2005; Longhurst, 2006; Power, 2005. While beyond the scope of this paper, I think this work has much to offer the concept of transrurality.)

A nature-culture continuum allows for an experienced materiality of places, alongside a conceived understanding of space, alongside memories of other places, to be incorporated within embodied experiences - absent rurals as well as absent natures to be formative of landscape. In this continuum, the spatiality of embodied practice is still becoming rather than fixed, but in a different process than that suggested by landscape-as-animating subjects alone. Tolia-Kelly's (2006a; 2007) work on the experiences of Asian migrant residents in northern England enables just such a more nuanced reading of complicated engagements with the English countryside, and seeks to:

"unravel multiple relationships embedded in visitor engagements with [the English countryside] and thus disrupt the moral geography of the landscape as embodying a singular English sensibility, normally exclusionary of British multi-ethnic, translocal and mobile landscape values and sensibilities." (Tolia-Kelly, 2007:329) 
Similarly, Milbourne (2007:385) argues a need to more carefully consider the "broad range of movements and mobilities that are being played out in rural spaces" (after Cresswell, 2006) to highlight that such migrations involve representation interconnected with material corporealities. Conceptualising nature as holding the potential for positive as well as negative experiences and connections with the English countryside, offers a way to re-conceive visible communities IN the countryside as well as further unpacking the processes that work to exclude them. As Panelli et al. (2008) outline, we need a multi-layered reading of place and ethnicity, and the ways in which different expressions of identity encompass place-specific and 'ethnically complex meanings'. Conceptualising across mobility, embodiment and the affective realm opens up to what Rose (2006) calls the 'dream of presence', in which people may access worlds/spaces/places and 'orient becoming in the face of alterity'15. Indeed, 'mobility is an important concept' for understanding how rurality may be experienced, performed, encountered in 'dynamic, embodied and highly politicised ways' (Merriman et al. 2008:209).

Visible communities, then, may predominantly experience everyday life in urban environments in England, but reflectively and emotionally embodied relationships with nature facilitate claims to being/belonging that cross spatialised boundaries such as rural/urban. A de-spatialised nature can be part of an additive model of belonging, with attachments felt in rural and urban space as well as in England and the West Indies, for example (see Rishbeth, 2001). Thus theorising rurality should incorporate experiences and social relations played out via its specific, inter-connecting and complex associations with a multitude of other spaces, increasingly given processes and practices of globalisation ${ }^{16}$. The English countryside can no longer be territorialized or racialised, but becomes 'a mobile, circulating and ubiquitous space' (Amin, 2004) - disrupting the very possibility of 'rural others' and enabling a more inclusive reading of visible communities' engagement with the English countryside.

\section{Towards the transrural}


Within rural studies, there has been increasing debate regarding 'differentiated countrysides' and increased pluralism in rural areas (Murdoch, 2006; Panelli, 2006). Recent work has focused on such issues as changes in rural populations (Dorling and Rees, 2003), shifts in rural social geographies (Smith and Holt, 2006), the wider spatial mobilities and social networks involved in rural living (Marsden, 2006), and 'radical rural spatialities' (Halfacree, 2007) - all of which challenges any notion of a homogenised, bounded English countryside. As Smith (2007:280) states, population flow into rural areas particularly:

"may be giving rise to significant transmutations of both abstract and material representations of rurality. It is likely that this will generate a growing fuzziness between contemporary social and cultural meanings of the rural, and the intersection of the urban and rural."

England is a multi-ethnic nation, thus issues regarding ethnic diversity are inherent within all nation spaces - whether spoken, unspoken, performed, ignored or denied, whether visible communities are present in or absent from the countryside (and beyond visitation, there are questions to be raised regarding visible community residence in rural villages). Academics and policy makers must engage with these issues if we are to avoid rescripting the rural as only white and non-white people as always already excluded from rural areas, further hiding structured identity production, racism and power relations in English society (see Bressey, 2009). Challenging these relationships involves uncovering, mapping and describing exclusions, crucially alongside being open to the ways in which diverse ethnic groups engage with and understand rurality.

Moreover, mindful of Ahmed's (2000) work, any conceptualisation of visible community Imaginaries and belongings must also probe the ways in which they are entangled with structured inequalities (also Hesse, 2000). So I'm not arguing for a 'post-rural' studies here. There remain powerful social productions regarding what 'the rural' is and means. While these productions may be gendered, racialised, aged, (dis)abled, sexualised etc. and therefore highly contested, they are also similar in that rurality can be 'known', can be constructed as rural ... I believe Cloke and Thrift's (1994:3) argument still holds:

"To accept the rural as a social and cultural construct allows the rural to be rescued as an important research category, as the way in which the meanings of rurality are constructed, 
negotiated and experienced will interconnect with the agencies and structures being played out in the space concerned."

What I am supporting is a transrural approach, which takes account of the specificities of place and, at the same time, pays closer attention to the ways in which rurality is implicated in and implicates other spaces and places, not only with regard to its binary 'the urban' but also networks of spaces and places across different scales. I agree with Smith (2007:277), that we should aim to "explore the links between locally distinctive and more general social change", situating our local rural research within wider societal processes and change. Indeed, Hoggart (2007) argues that we need to excavate the interactions across rural and urban areas in 'city-regions' if we are to understand 'geographies of disadvantage and opportunity', calling for a regional perspective (see also Murdoch, 2006). Certainly, theorising around 'regions unbound' (Amin, 2004) and the new spatialisations of city-regions (Painter, 2007) are valuable contributions to a transrural perspective. But there is also an urgent need to extend such work's thinking on class, and interpretations of poverty, social polarisation and deprivation in rural areas, to include more consideration of ethnicity in these issues.

In addition, I would argue the need to position rural places within broader national and transnational processes in an ever-more mobile and interconnected world. Milbourne (2007:384) points out that "little critical attention has been given to processes of international migration impacting on rural areas", calling for further scrutiny of two particular movements: low-income migrant workers from Eastern and Central European countries into English rural areas (Commission for Rural Communities, 2007); and international 'lifestyle' migration to rural areas across northern Europe, creating 'new forms of international rural spaces'. While Anderson et al. (2006) and Rogaly (2006) are importantly beginning to address the first of these migrations, Hubbard's (2005) work regarding rural anti-asylum campaigns resisting in-movement of ethnic minority groups, and Holloway's (2007) research exploring the experiences of traveller communities in rural England, also speak to such broader national and transnational processes.

More than the impact of movement into rural areas by minority groups, though, theorising rurality should also take account of how national and transnational processes are part of people's constructions of the rural, whether they move there or not. Following this, l'd like to suggest that a 
'transrural' perspective opens up rural studies to engaging in more primary empirical work beyond the countryside. I would hazard a guess that many 'rural academics' live and/or work in urban areas, and we are already crossing spatial divides as part of everyday life. Exploring what 'transrural' may mean will involve moving and being - embodying, sensing, reflecting - across a range of spaces.

\section{Acknowledgements}

To my family, for allowing me to question their thoughts and feelings around the issues addressed here. I am also forever indebted to all those who contributed to the $\mathrm{PhD}$ research in any way, especially the Mosaic Project staff and participants: equally my gratitude goes to everyone involved in my recent/current research. I would like to thank my PhD supervisors for their invaluable guidance and help through that journey, and the editors and anonymous referees for their patience with and insightful comments on the earlier draft of this paper. It never fails to amaze me that folk are willing to give their time and energy to engage with research. I constantly fear that I'm not up to the task: any mistakes/misrepresentations/lack of clarity or coherence etc in this paper are entirely my own shortcomings.

\section{References}

Agyeman, J. (1995) Environment, heritage and multiculturalism. Interpretation: A Journal of Heritage and Environmental Interpretation, 5-6.

Agyeman, J. and Spooner, R. (1997) Ethnicity and the rural environment. In Contested Countryside Cultures. Routledge, pp. 197-217, Cloke, P., and Little, J. (eds.). Routledge, London.

Ahmed, S. (2000) Strange Encounters: Embodied Others in Post-Coloniality. Routledge, London.

Alexander, C. (2000). The Asian Gang. Berg, London.

Alibhai-Brown, Y. (2001) Who do we think we are? Imagining the New Britain. Penguin, London. 
Amin, A. (2002) Ethnicity and the Multicultural City: living with diversity. Environment and Planning A $34,959-980$.

Amin, A. (2004) Regions Unbound: Towards a new politics of place. Geografiska Annaler 86B (1), 1944.

Anderson, B. and Tolia-Kelly, D. (2004). Matter(s) in social and cultural geography. Geoforum 35, 669-674.

Anderson, B., Ruhs, M., Rogaly, B. and Spencer, S. (2006). Fair enough? Central and East European migrants in low-wage employment in the UK. Joseph Rowntree Foundation, York. Available at http://www.jrf.org.uk/bookshop/eBooks/1617-migrants-low-wage-employment.pdf

Anderson, K. (1995). Culture and nature at the Adelaide Zoo: at the frontiers of 'human' geography. Transactions of the Institute of British Geographers 20, 275-294.

Askins, K. (2006) New countryside? New country: visible communities in the English national parks. In The New Countryside? Ethnicity, Nation and Exclusion in Contemporary Rural Britain, pp. 149-172, Neal, S. and Agyeman, J. (eds.). Policy Press, London.

Askins, K. (2008) (re)negotiations: towards a transformative geopolitics of fear and otherness. In Fear: Critical Geopolitics and Everyday Life, pp. 235-248, Pain, R. and Smith, S. (eds.). Ashgate, London.

Back, L. and Solomos, J. (eds.) (2003) Theories of Race and Racism: a Reader. Routledge, London.

Bondi, L. (ed.) (2002) Subjectivities, Knowledges, and Feminist Geographies. Rowman and Littlefield, Oxford.

Brah, A., Hickman, M. J. and Mac an Ghaill, M. (eds.) (1999) Thinking Identities: Ethnicity, Racism and Culture. Macmillan Press, London.

Braun, B. (2002) Colonialism's afterlife: vision and visuality on the Northwest Coast. Cultural Geographies 9(2), 202-237. 
Bressey, C. (2009). Cultural archaeology and historical geographies of the black presence in rural Britain. Unpublished typescript.

Cloke, P. and Little, J. (1997) Contested Countryside Cultures. Routledge, London.

Cloke, P., Milbourne, P. and Thomas, C. (1996) The English National Forest: local reactions to plans for renegotiated nature-society relations in the countryside. Transactions of the Institute of British Geographers 21, 552-571.

Cloke, P. and Thrift, N. (1994) Introduction: Refiguring the 'Rural'. In Writing the Rural: five cultural geographies, pp. 1-5, Cloke, P., Doel, M., Matless, D., Phillips, M. and Thrift, N. (eds.). Paul Chapman Publishing Ltd., London.

Commission for Rural Communities (2007) A8 Migrant Workers in Rural Areas. Commission for Rural Communities, London.

Dorling, D. and Rees, P. (2003) A nation dividing? Some interpretations of the question. Environment and Planning A 26, 369-373.

Edensor, T. (2007). Sensing the ruin. The Senses and Society 2(2), 217-232.

Franklin, A. (2002) Nature and Social Theory. Sage, London.

Geertz, C. (1963) Old Societies and New States - The Quest for Modernity in Asia and Africa. Free Press, Illinois.

Gilroy, P. (2001) Against Race: Imagining political culture beyond the color line. Harvard University Press. Cambridge.

Halfacree, K.H. (2007) Trial by space for a 'radical rural': Introducing alternative localities, representations and lives. Journal of Rural Studies 23, 125-141.

Hall, S. (2003) Old and New Identities, Old and New Ethnicities. In Theories of Race and Racism: A Reader, pp. 144-153, Back, L. and Solomos, J. (eds.). Routledge, London. 
Harrison, C. and Burgess, J. (1994) Social constructions of nature: a case study of conflicts over the development of Rainham Marshes. Transactions of the Institute of British Geographers 19, 291-310.

Henderson, P. and Kaur, R. (eds.) (1999) Rural Racism in the UK: Examples of Community-Based Responses. Community Development Foundation, London.

Hesse, B. (ed.) (2000) Un/settled Multiculturalisms: Diasporas, Entanglements, Transruptions. Zed Books, London.

Hetherington, K. (1997) In places of geometry: the materiality of place. In Ideas of Difference, pp. 183199, Hetherington, K. and Munro, R. (eds.). Blackwell, Oxford.

Hetherington, K. (2003) Spatial textures: place, touch and praesentia. Environment and Planning A 35(11), 1933-1944.

Hinchcliffe, S., Kearnes, M.B., Degen, M. and Whatmore, S. (2005) Urban wild things: a cosmopolitical experiment. Environment and Planning D 23(5), 643-658.

Hoggart, K. (2007). The diluted working classes of rural England and Wales. Journal of Rural Studies 23 (3), 305-317.

Holloway, S. (2007). Burning issues: whiteness, rurality and the politics of difference. Geoforum 38, 720.

Hubbard, P. (2005) 'Inappropriate and incongrous': opposition to asylum centres in the English countryside. Journal of Rural Studies 21, 3-17.

Ingold, T. and Lee, J. (2008) Ways of walking: ethnography and practice on foot. Ashgate, London.

Jackson, P. (2000) Rematerializing social and cultural geography. Social and Cultural Geography 1, $9-14$

Katz, C. (1998) Whose nature, whose culture? In Remaking Reality: nature at the millennium, pp. 4663, Castree, N. and Braun, B. (eds.). Routledge, London. 
Kearns, M.B. (2003) Geographies that matter - the rhetorical deployment of physicality? Social and Cultural Geography 4(2), 139-152.

Kinsman, P. (1995) Landscape, race and national identity: the photography of Ingrid Pollard. Area 27(4), 300-310.

Kobayashi, A. (1994) Coloring the Field: Gender, "Race", and the Politics of Fieldwork. Professional Geographer 46(1), 73-80

Little, J. (1999). Otherness, representation and the cultural construction of rurality. Progress in Human Geography 23(3), 437-442.

Little, J. (2002) Rural geography: rural gender identity and the performance of masculinity and femininity in the countryside. Progress in Human Geography 26(5), 665-670.

Little, J. and Austin, P. (1996) Women and the Rural Idyll. Journal of Rural Studies 12(2), 101-111.

Longhurst, R. (2006) Plots, plants and paradoxes: contemporary domestic gardens in Aotearoa NewZealand. Social and Cultural Geography 7(4), 581-593.

Lorimer, H. (2008). Cultural geography: non-representational conditions and concerns. Progress in Human Geography 32(4), 551-559.

Lowenthal, D. (1997) Empires and ecologies: reflections on environmental history. In Ecology and Empires: Environmental History of Settler Societies, pp. 229-238, Griffiths, T. and Libby, R. (eds.). University of Washington Press, Seattle.

MacNaughton, P. and Urry, J. (2000) Bodies of Nature: Introduction. Body \& Society 6(3-4), 1-11.

Macpherson, H.M. (2009a) The inter-corporeal emergence of landscape: negotiating sight, blindness and ideas of landscape in the British Countryside. Environment and Planning A: Society and Space forthcoming.

Macpherson, H.M. (2009b) Touch in the countryside: memory and visualization through the feet. The Senses and Society 4(2), forthcoming. 
Malik, S. (1992) Colours of the countryside - a whiter shade of pale. ECOS 9(3), 33-40.

Mardsen, T. (2006) Pathways in the sociology of rural knowledge. In Handbook of Rural Studies, pp. 3-17, Cloke, P., Marsden, T. and Mooney, P.H. (eds.). Sage, London.

Massey, D. (2006) Landscape as provocation. Journal of Material Culture 11(1/2), 33-48.

Massey, D. (2004). Geographies of responsibility. Geografiska Annaler 86 B (1), 5-18.

Massumi, B. (2002) Parables for the virtual: movement, affect, sensation. Duke University Press, London.

Matless, D. (1998) Landscape and Englishness. Reaktion Books, London.

Merriman, P., Revill, G., Cresswell, T., Lorimer, H., Matless, D., Rose, G. and Wylie, J. (2008) Lanscape, mobility, practice. Social and Cultural Geography 9(2), 191-212.

Milbourne, P. (ed.) (1997) Revealing Rural Others: Representation, Power and Identity in the British Countryside. Pinter, London.

Milbourne, P. (2007) Re-populating rural studies: Migrations, movements and mobilities. Journal of Rural Studies 23, 381-386.

Mirza, H. S. (1997) Black British Feminism: A reader. Routledge, London.

Modood, T. (1992) Not Easy Being British: Colour, Culture and Citizenship. Runnymede Trust and Trentham Books, Stoke on Trent.

Murdoch, J. (2006) Networking rurality: emergent complexities in the countryside. In Handbook of Rural Studies, pp.171-184, Cloke, P., Marsden, T. and Mooney, P.H. (eds.). Sage, London.

Nakashima, K. (2003) Self and others in the social construction of nature. Paper presented to the Association of American Geographers Annual Meeting, New Orleans, March 2003. 
Neal, S. (2002) Rural landscapes, representations and racism: examining multicultural citizenship and policy-making in the English countryside. Ethnic and Racial Studies 25(3), 442-461.

Neal, S. and Agyeman, J. (eds.) (2006) The New Countryside?: Ethnicity, Nation and Exclusion in Contemporary Rural Britain. Policy Press, London.

Neal, S. and Walters, S. (2006) Strangers asking strange questions? A methodological narrative of researching belonging and identity in English rural communities. Journal of Rural Studies 22, 177189.

NYM (2003) Social Inclusion: a special report from the 2003 National Park Society Conference. Voice of the Moors 74(2), 9-17.

O'Riordan, R. (1989) The Challenge for Environmentalism. In New Models in Geography: Volume One, pp. 77-102, Peet, R. and Thrift, N. (eds.). Unwin Hyman, London.

Painter, J. (2007) City-regions and the spatialities of urban-rural relations. Paper presented at Regions and Regionalism in and beyond Europe, Colloquim 3: Urban-Rural: Flows and Boundaries, 9-10 January http://www.lancs.ac.uk/ias/annualprogramme/regionalism/docs/Painter paper.pdf

Panelli, R. (2006) Rural Society. In Handbook of Rural Studies, pp. 63-90, Cloke, P., Marsden, T. and Mooney, P.H. (eds.). Sage, London.

Panelli, R., Allen, D., Ellison, B., Kelly, A., John, A. and Tipa, G. (2008) Beyond Bluff Oysters? Place identity and ethnicity in a peripheral coastal setting. Journal of Rural Studies 24 (1), 41-55.

Parekh, B. (2000a) The Future of Multi-Ethnic Britain. Profile Books, London.

Parekh, B. (2000b) Rethinking Multiculturalism: Cultural Diversity and Political Theory. Palgrave, London.

Parr, H. (2007) Mental health, nature work, and social inclusion. Environment and Planning D: Society and Space 25(3), 537-561. 
Pink, S. (2007) Sensing Cittaslow: Slow Living and the Constitution of the Sensory City. The Senses and Society 2(1), 59-77.

Power, E.R. (2005) Human-nature relations in suburban gardens. Australian Geographer 36(1), 3953.

Probyn, E. (2005) Blush: faces of shame. University of Minnesota Press, Minneapolis.

Ray, L. and Reed, K. (2005) Community, mobility and racism in a semi-rural area: Comparing minority experience in East Kent. Ethnic and Racial Studies 28(2), 212-234.

Rishbeth, C. (2001) Ethnic Minority Groups and the Design of Public Open Space: an inclusive landscape? Landscape Research 26(4), 351-366.

Robinson, D. (2008) Community Cohesion in Crisis? New Dimensions of Diversity and Difference. Policy Press, Bristol.

Rogaly, B. (2006) Intensification of Work-Place Regimes in British Agriculture: The Role of Migrant Workers, SUSSEX MIGRATION WORKING PAPER 36. Available at http://www.sussex.ac.uk/migration/documents/mwp36.pdf

Rose, G. (1997) Situating knowledges: positionality, reflexivities and other tactics. Progress in Human Geography 21, 305-320.

Rose, M. (2006) Gathering 'dreams of presence': a project for the cultural landscape. Environment and Planning D: Society and Space 24(4), 537-554.

Rye, J.F. (2006) Rural youths' images of the rural. Journal of Rural Studies 22, 409-421.

Scruton, R. (2001) England: an Elegy. Pimlico, London.

Sivanandan, A. (2001) Poverty is the new black. Race \& Class 43(2), 1-7.

Smith, D. (2007) The changing faces of rural populations: "(re)Fixing" the gaze' or 'eyes wide shut'? Journal of Rural Studies 23, 275-282. 
Smith, D. and Holt, L. (2006) Lesbian migrants in the gentrified valley and 'other' geographies of gentrification. Journal of Rural Studies 21, 313-322.

Tolia-Kelly, D.P. (2004) Landscape, Race and Memory: Biographical Mapping of the Routes of British Asian Landscape Values. Landscape Research 29(3), 277-292.

Tolia-Kelly, D.P. (2006a) Mobility/stability: British Asian cultures of 'landscape and Englishness'. Environment and Planning A 38(2), 341-358.

Tolia-Kelly, D.P. (2006b) Affect - an Ethnocentric Encounter?: Exploring the 'universalist' imperative of emotional/affectual geographies. Area 38(2), 213-217.

Tolia-Kelly, D.P. (2007) Fear in Paradise: The Affective Registers of the English Lake District Landscape Re-visited. Senses \& Society 2(3), 329-351.

Whatmore, S. (1999) Culture - nature. In Introducing Human Geographies, pp. 4-11, Cloke, P., Crang, P. and Goodwin, M. (eds.). Arnold, London.

Whatmore, S. (2002) Hybrid geographies: natures, cultures, spaces. Imprint, London.

Wylie, J. (2005) A Single Day's Walking: Narrating Self and Landscape on the South West Coast Path. Transactions of the Institute of British Geographers 30, 234-47.

\section{Footnotes}

${ }^{1}$ The National Park Authorities use capital letters for themselves; I have never capitalised 'national parks' in my writing/work because many respondents/participants in the research had never heard of national parks in the sense of organised/legitimised places governed by official bodies ... rather as fairly nebulous areas of countryside, if at all.

${ }^{2}$ The PhD was an ESRC CASE funded project, with the North York Moors national park as CASE partner. The policy document is available at

http://www.visitnorthyorkshiremoors.co.uk/content.php?nID=675.

${ }^{3} \mathrm{I}$ am writing here from a generalised Western and European position - debate regarding rurality, ethnicity and spatial in/exclusions from an elsewhere perspective has its own specificities. 
${ }^{4} 24 \%$ and $30 \%$ of respondents in Middlesbrough and Sheffield respectively stated that they had visited the English countryside on at least one occasion.

${ }^{5}$ There are methodological concerns regarding this statistic, though, in that 'random sampling' was skewed by potential respondents' dis/interest in the survey themes: many white visitors declined to participate, while the majority of visible community visitors approached agreed to take part.

${ }^{6}$ Interviewees were all British citizens, roughly one third first generation immigrants, the rest second and third generation. Everyone was asked to describe their ethnicity without a given list, and these self-selected definitions are used with quotes throughout this paper.

${ }^{7}$ See http://www.mosaicpartnership.org/.

${ }^{8}$ This was a key issue for National Park Authorities in policy terms, and speaks to visible community exclusions - but not my direct concern in this paper (see Askins, 2006).

${ }^{9}$ This is not to suggest that all people from the 'majority culture' in England attach such importance to nature or the countryside - and I echo Hubbard's (2005) argument that some social groups are more 'white' than others when it comes to claiming the dominant rural idyll Imaginary. Rather I suggest that the dominant representation encountered in the study involved such an assumption.

${ }^{10}$ See www.mosaicpartnership.org, regarding the on-going work, managed by the CNP, since the Mosaic Project.

${ }^{11}$ See www.ben-network.org.uk.

${ }^{12}$ It is not my intention to suggest any easy commonality across Asian, African and Caribbean groups. However, in this particular research context there were greater distinctions evident between age, gender and class than between visible community ethnicities, to which I return later in the paper.

${ }^{13} 52 \%$ of the urban respondents in this age bracket stated that lack of interest was the key reason they did not visit the countryside.

${ }^{14}$ I recognise that this is an over-simplified argument: see Rye's (2006) detailed study on rural youths' images of the rural.

${ }^{15}$ I am indebted to Hannah Macpherson for drawing my attention to Rose's point here.

${ }^{16}$ Implicit within my argument is Massey's (2004) contention that alongside 'locality' or place as the scale of environment (grounded and real) able to render 'sense of place', space also has the capacity to be meaningful. Such a reading of space and place as themselves relational is particularly important 
when theorising ethnicity and rurality, given the issues regarding diasporic identity and international connections caught up in visible community histories, experiences and day-to-day lives. 


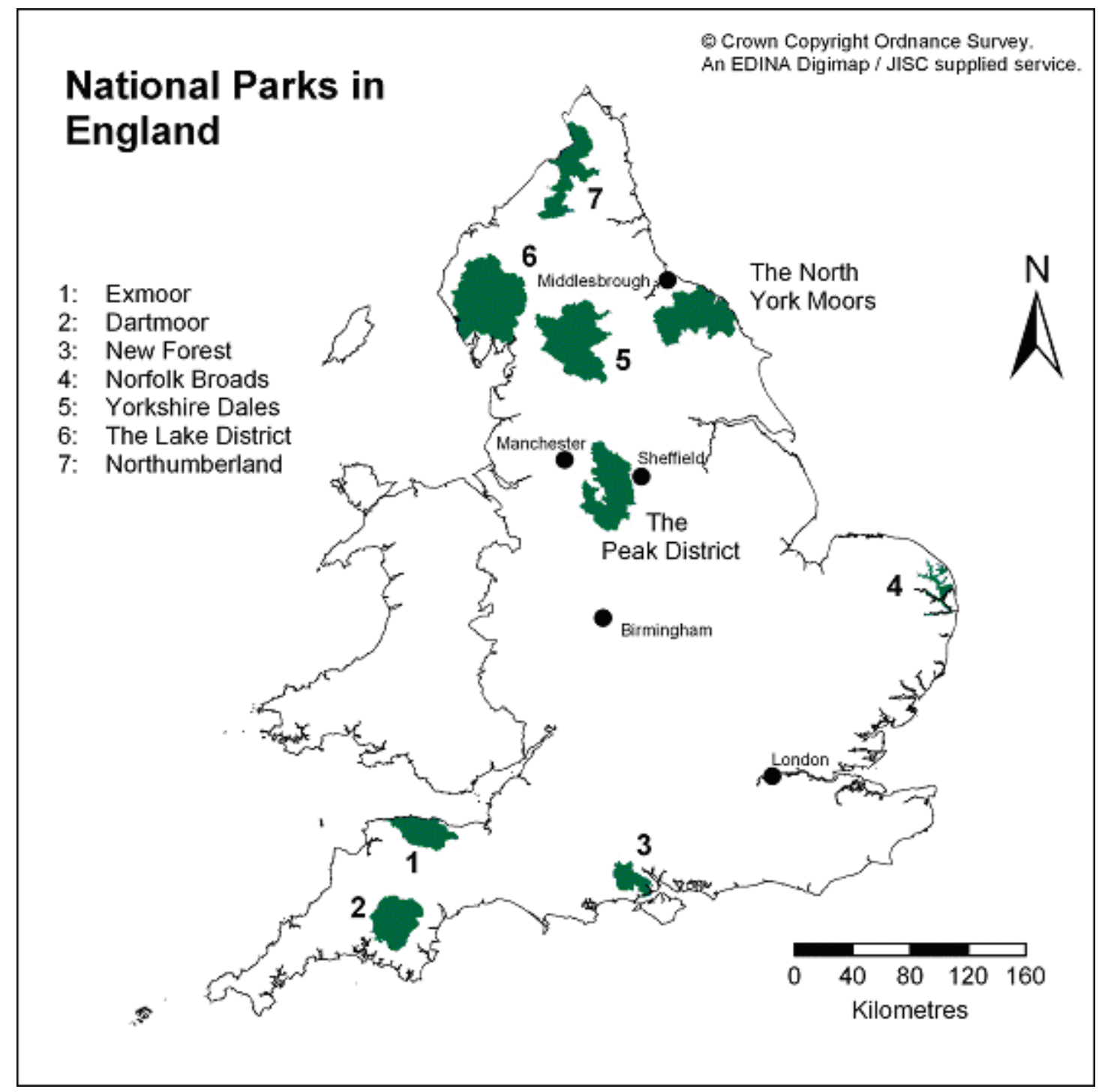

Figure 1: Map of the national parks in England, indicating the research areas. 


\begin{tabular}{|l|c|}
\hline "Nature plays an important part in your sense of self identity" & $\begin{array}{l}\text { visible community } \\
\text { respondents } \\
\% \quad(n=606)\end{array}$ \\
\hline strongly agree & 19 \\
\hline agree & 43 \\
\hline no opinion & 24 \\
\hline disagree & 10 \\
\hline strongly disagree & 4 \\
\hline
\end{tabular}

Table 1: visible community responses to the statement "Nature plays an important part in your sense of self identity." 
Figure 1: Map of the national parks in England, indicating the research areas.

Figure 2: Visiting a plant nursery in the NYM.

Figure 3: Dynamic embodiment in the countryside.

Figure 4: Reflective embodiment - countryside or urban park?

Table 1: Visible community responses to the statement "Nature plays an important part in your sense of self identity." 